\title{
Subsequent vaginal delivery in a case reverted by Dobbins operation for acute uterine inversion: A case report
}

\author{
Ashma Rana, Geeta Gurung, Jitendra Pariyar, Sunil Pokharel, Shilu Adhikari \\ Dept of Ob/Gyn, TU Teaching Hospital
}

\begin{abstract}
A woman with a history of laparotomy and corrective abdominal surgery for acute puerperal uterine inversion reverted by division of the inversion ring anteriorly "Dobbins's operation" subsequently was successful to undergo assisted vaginal breech delivery arriving at second stage of labor warranting, manual removal of placenta which was complied with the management of PPH.

This case is reported because of the rarity of uterine inversion itself in the first place. Next because of the conception taking place spontaneously after morbid puerperal period and then the pregnancy advancing to term: all the management beginning from correction of uterine inversion to retained placenta being handled in the same facility a rare event too in our set up.
\end{abstract}

Key words: Uterine inversion and subsequent birth, manual removal of the placenta.

\section{Introduction}

Subsequent birth after reposition of inverted puerperal uterine inversion has been described in 29 out of 46 cases, this case being unique in the sense that, both the management of puerperal uterine inversion and vaginal birth with retained placenta in the subsequent delivery was carried in our facility under same team of doctors which is reported here. ${ }^{1-2}$

\section{Case}

Three years back an 18 year old adolescent primipara had been referred to us as a case of puerperal uterine inversion, assumed to be due to 'pulling on to the cord simultaneously at the time of mother's full bearing down force', thus coping placental delivery. Inversion was detected because of acute abdominal pain and severe postpartum hemorrhage (PPH) which occurred after 12 hours of spontaneous vaginal delivery of a baby girl weighing $2500 \mathrm{Gms}$.

In our hospital, loss of uterine fundus abdominally and discovery of inverted cup vaginally exposing the endometrial surface reconfirmed the diagnosis. Laparotomy was done to cut open the resilient inversion ring anteriorly "Dobbins operation" and to release all the structures (ovary, tubes and round ligament) pulling in through this hole. After successful reversion (Fig 3), management of atonic PPH by oxytocics, endometritis by antibiotics enthusiastically and correction of anemia by adequate blood transfusion. At discharge she was counseled for hospital delivery in the case of subsequent pregnancies. ${ }^{3}$

She came to us 3 years later. She was breast feeding. In the antenatal check up uterine size corresponded to the history of amenorrhea which was confirmed by Trans Vaginal Ultrasound (TVS) to be 9 weeks of gestational age. She was then followed up regularly until 34 weeks of pregnancy. Till this time every thing seemed to progress normally. The obstetric plan was to allow vaginal delivery. She was then lost to follow up and was admitted in second stage of labor with ruptured amniotic membranes at $39^{+2}$ weeks period of gestation, with extended breech in left sacroanterior position (LSA). Within 20 minutes of arrival, an assisted vaginal breech delivery of a live baby girl was

Correspondence

Dr. Ashma Rana, MD FICS.

Prof. Dept of Obs/Gyn TUTH, Nepal

E mail: prof.drranaa@hotmail.com 


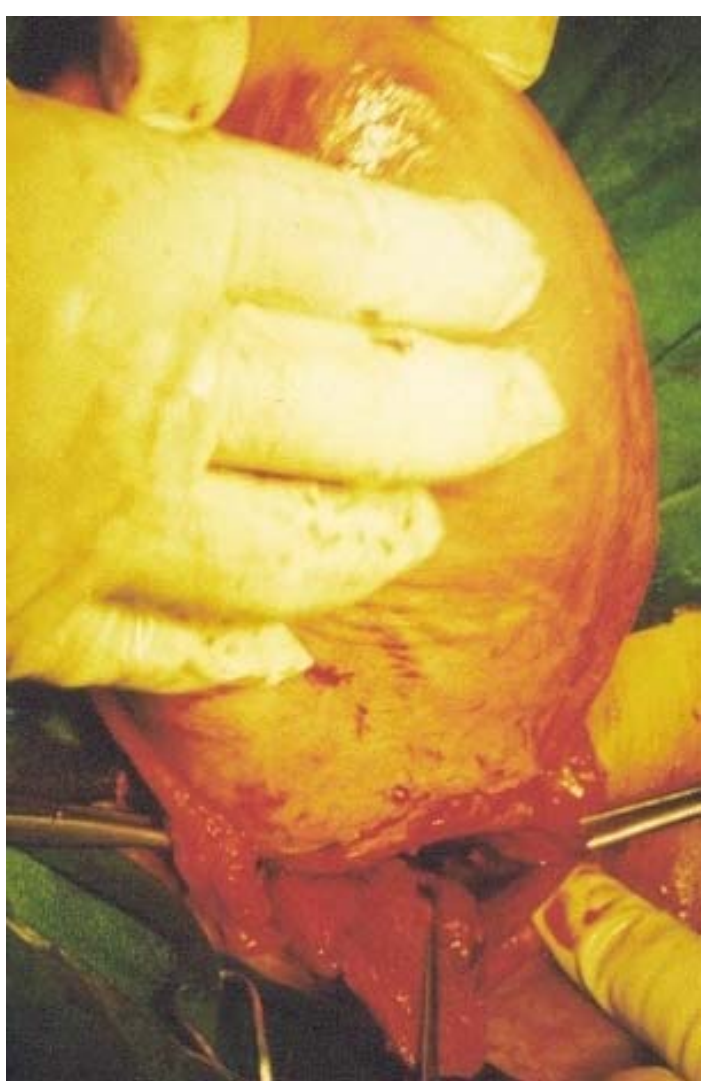

Figure I. Uterine inversion reverted at laparotomy.

accomplished weighing $2750 \mathrm{Gms}$ with good Apgar score of $7 / 10,8 / 10$; at one and five minutes of birth respectively. As a part of active management of the third stage, prophylactic oxytocin $10 \mathrm{U}$ had been administered intramuscularly just after the birth and the delivery of the placenta was attempted by controlled cord traction when the uterus contracted. There was partial delivery of placenta which appeared in the vagina (Fig 2). But most of it was found to be morbidly adherent to the posterior part of the body of the uterus during manual removal of placenta which was performed under general anesthesia in about $1 \frac{1}{2}$ hours. The placenta was ragged but complete and weighed $480 \mathrm{gms}$. There was atonic postpartum hemorrhage which was controlled by bimanual uterine massage, i.v infusion of oxytocin $40 \mathrm{U}$ in a drip and two doses of $250 \mathrm{mgm}$ of prostaglandin $\mathrm{F}_{2}$ á, one given intramyometrially and the second dose repeated in 30 minutes intramuscularly. The total estimated blood loss was $1500 \mathrm{ml}$ and total 3 units of whole blood were transfused. As the uterus was flabby, to prevent reversion and postpartum hemorrhage tight uterine and vaginal packing was accomplished. To keep the uterus contracted, oxytocin infusion was continued for $24 \mathrm{hrs}$ until the pack was removed vaginally (Fig 3 ). She was discharged with her baby after a week ensuring that there was no inversion and uterine involution was satisfactory.

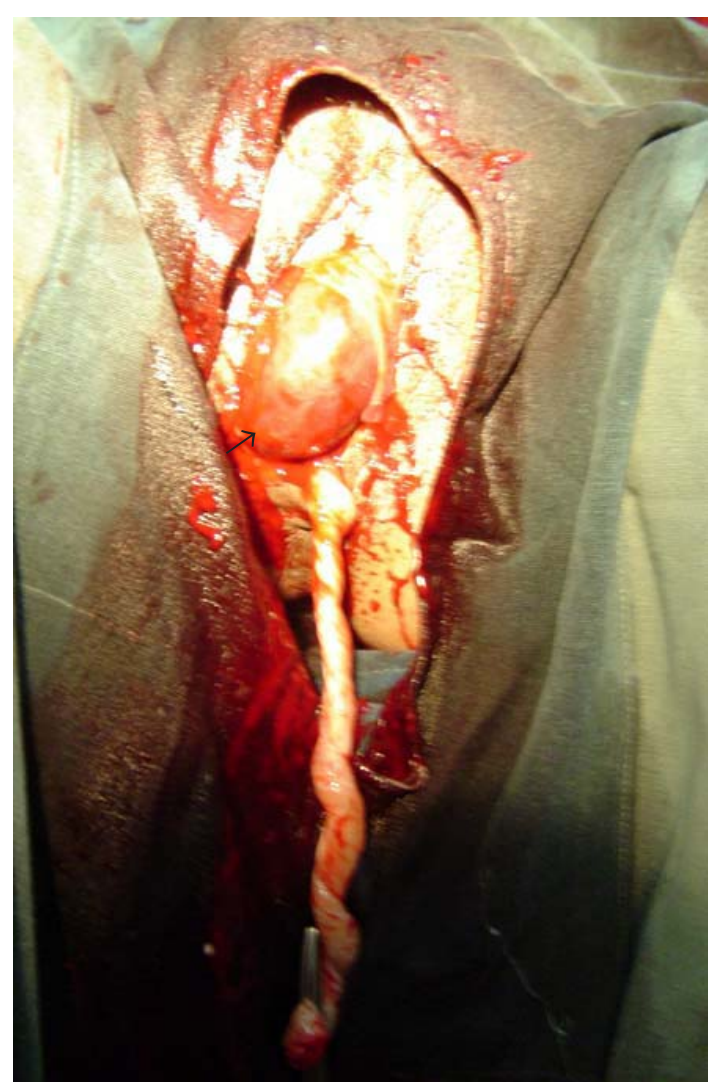

Figure 2. Placenta apparently looks as though half separated, but is retained within the uterus. A big clot has been formed, which looks like placental tissue.

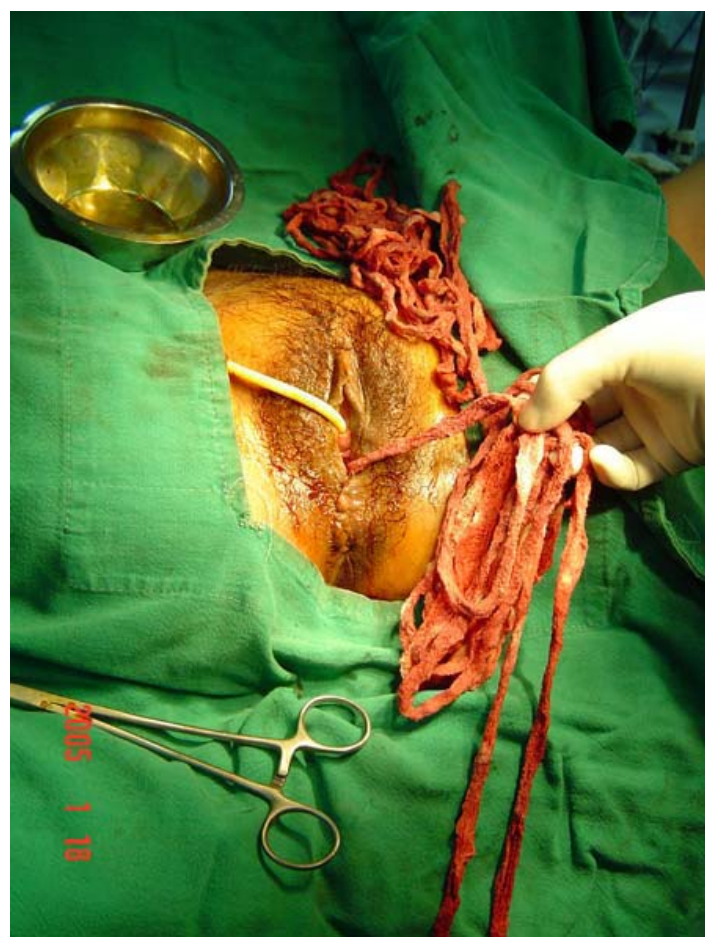

Figure 3. Removing intrauterine and vaginal pack 


\section{Comment}

Puerperal uterine inversion is an uncommon lifethreatening obstetric emergency situation, amending repositioning of uterine fundus manually or in failure to do so abdominally by laparotomy and corrective reverting procedures, which in this case was performed by Dobbins operation. ${ }^{3}$ The advantage of this surgical procedure expressed being the placement of the incision anteriorly in the lower part of the uterus like in a lower segment caesarean section such that safely vaginal delivery could be advocated during future child bearing. It is not less surprising that this woman resumed normal menstruation despite massive $\mathrm{PPH}$, where one would theoretically be threatened to accept pituitary failure and secondary amenorrhoea. It is also surprising that there was conception that continued to term despite the fact that there had been an extended period of puerperal morbidity from puerperal pyrexia originating from endometritis. Root of genital sepsis then, related to multiple vaginal examinations for the diagnosis of uterine inversion and innumerable vaginal manipulations for the correction in two different set up, one very far from us. Having her come to us again in her subsequent pregnancy is not less surprising, where majority of the women are lost to follow up in this part of the world.

Coming to the crux of the matter, as up to date very little number of cases has been published following correction of uterine inversion and there are even lesser number after surgical correction. This is not because of the surgical procedure itself but because of the circumstance and time that must have elapsed before the effort has been made.

There has been record of two pregnancy following Haultain's operation that ended in vaginal live biths in Indian set up, while two pregnancies in a single woman that needed emergency caesarean for obstetric causes following manual reposition of the uterus by Johnson's method. A review at least gave insight to 26 of the 40 cases who were observed to have no further inversion in the subsequent delivery. ${ }^{2}$

Massive postpartum hemorrhage, morbid placental adhesion and placenta accreta are the usual complication one anticipates at subsequent birth as in our case. ${ }^{4}$ Safety of the Dobbins operation as anticipated has been recognized from the fact that the site of placental adherence was far away from our uterine incision site made during the time of reversion of the uterine inversion in the past.

Although there are recommendations for safe elective caesarean delivery at the hands of experts, one of the reasons, may be because of the fear of placental retention that can be well taken care of instantaneously at caesarean, often one would speculate lesser hesitation to remove the uterus, should atonicity be a complication during caesarean compared to vaginal delivery, where the question of sacrificing the uterus is the last mandate. At or after vaginal delivery, one is rather expected to try out whole ranges of uterine conserving remedies even at the face of torrid hemorrhage, before being tempted towards hysterectomy.

\section{Conclusion}

Pregnancy following surgical correction of uterine inversion can be allowed to deliver vaginally, especially being watchful for the third stage complication like PPH and morbid placental adhesion (placenta accreta) which might necessitate not only manual removal of placenta but also major obstetric interventions such as hysterectomy.

\section{References}

1. Sinha G, Sinha A. Fertility and reproduction following inversion of uterus. J Indian Med Assoc. 1993 Jun; 91(6):149-50.

2. Baskett TF Acute uterine inversion: a review of 40 cases J Obstet Gynaecol Can. 2002 Dec; 24(12):953-6.

3. Ashma Rana, Neelam Pradhan, Kanti Giri. Diki Bista, Jay K. Thakur. Acute uterine inversion reverted by laparotomy and division of ring anteriorly, Dobbins operation. Singapore J of Obs/ Gyn 2002; 33(3):50-54.

4. Tank Parikshit D, Mayadeo Niranjan M, Nandanwar YS. Pregnancy outcome after operative correction of puerperal uterine inversion. Arch Gynecol Obstet. 2004 Mar; 269(3):214-6. Epub 2002. 